\title{
FVDZ startet Studentenparlament
}

Zahnärzte im Arztvergleich besonders beliebt

\section{Zufriedene Patienten}

Die deutschen Großstädter sind zufrieden mit ihren Ärzten und besonders zufrieden mit ihren Zahnärzten. Das zeigt eine aktuelle Umfrage des Arztbewertungsportals jameda zur Patientenzufriedenheit in den zehn größten Städten Deutschlands.

Darin werden die Mediziner von ihren Patienten im Schnitt mit der Note 1,71 bewertet. Am zufriedensten sind die Patienten in München: Dort bewerteten Patienten ihre Ärzte mit der Note 1,49. Platz zwei belegen die Düsseldorfer $(1,51)$ und Platz drei die Kölner Mediziner $(1,64)$.

Im Vergleich der Fachärzte kommen die Dermatologen mit der Note 2,21 am schlechtesten weg. Das Schlusslicht des Vergleichs bildet Leipzig: Die Patienten der größten Stadt in Sachsen gaben ihren Ärzten durchschnittlich die - immer noch gute - Note 1,9 .

Vor allem Zahnmediziner schneiden auf der Beliebtheitsskala sehr gut ab. Absolute Spitzenreiter sind die Zahnärzte in Düsseldorf (Note 1,19).

Zufrieden sind die Großstadtbewohner mit den Wartezeiten auf Termine (Note 1,79). Besonders gut mit der Note 1,38 schnitten hier die Praxen ab, die ihren Patienten eine Möglichkeit zur Online-Terminbuchung anbieten.

Deutlich sind übrigens die Unterschiede zwischen gesetzlich und privat Versicherten: Patienten der PKV benoten in den deutschen Großstädten ihre Ärzte deutlich besser als gesetzlich Versicherte. Dies weist auf mögliche Unterschiede in der Betreuung von Kassen- und Privatpatienten hin.

$m r$

\section{Krankenkassen-Überschuss}

\section{GKV-Finanzreserven steigen}

Die gesetzliche Krankenversicherung (GKV) hat das Jahr 2016 mit einem Finanzpolster von 25 Milliarden Euro abgeschlossen. Das gab das Bundesministerium für Gesundheit (BMG) im März bekannt. Demnach setzen sich die GKV-Reserven aus den Rücklagen der Krankenkassen (15,9 Milliarden Euro) und des Gesundheitsfonds (9,1 Milliarden Euro) zusammen.

Wie aus den Zahlen des BMG hervorgeht, erzielten allein die gesetzlichen Krankenkassen 2016 einen

Überschuss von rund 1,38 Milliarden

Euro. Im Vergleich dazu gaben die Kassen 2015 noch etwa 1,13 Milliarden
Zur nächsten Hauptversammlung lädt der Freie Verband offiziell Studenten ein, um aktiv daran teilzunehmen. Die knapp 5.000 studentischen Mitglieder bekommen auf diese Weise eine Möglichkeit, aktiv mitzugestalten und den politischen Prozess mit anzustoßen. Nicht mehr nur mit im Boot zu sitzen, sondern mitrudern, lautet die Devise. „Wir möchten Studenten von Anfang an in den politischen Prozess einbeziehen. Gemeinsam mit engagierten Studenten setzen wir uns dafür ein, die Situation an den Hochschulen zu verbessern um einen guten Berufsstart zu ermöglichen“, erklärt FVDZ-Bundesvorsitzender Harald Schrader die Zielsetzung des neu gegründeten Studentenparlaments.

Schon jetzt haben sich zahlreiche interessierte Studenten gemeldet. Gemeinsam mit dem Bundesvorstand arbeitet der für das Parlament gegründete Ausschuss derzeit intensiv an einem umsetzbaren Konzept. Bereits auf der Hauptversammlung im Oktober wird das erste FVDZ-Studentenparlament mit den Delegierten tagen.

Fragen dazu beantwortet Marvin Berchem unter mb@fvdz.de.

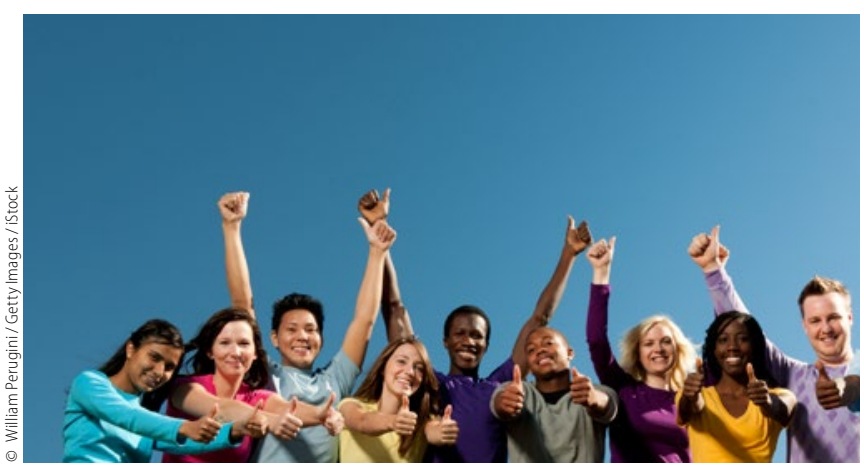

Euro mehr aus, als sie einnahmen. Das BMG begründet das gute Finanzergebnis mit dem Ausgabenanstieg von 3,3 Prozent je Versichertem. Dies sei der niedrigste Anstieg seit 2012 und liege damit deutlich unter der Voraussage des Schätzerkreises. Dieser hatte für 2016 noch einen Anstieg von 4,3 Prozent prognostiziert.

Beim Vergleich der Finanzentwicklung der einzelnen Kassen zeigen sich deutliche Unterschiede: Den höchsten Überschuss verbuchten demnach die Allgemeinen Ortskrankenkassen mit rund 935 Millionen Euro. Die Ersatzkassen erzielten einen Überschuss von 321 Millionen Euro, die Betriebskrankenkassen erzielten 29 Millionen Euro, die Knappschaft-Bahn-See 100 Millionen Euro und die landwirtschaftliche Krankenversicherung 34 Millionen Euro. Lediglich die Innungskrankenkassen kamen auf ein Defizit von rund 33 Millionen Euro. 